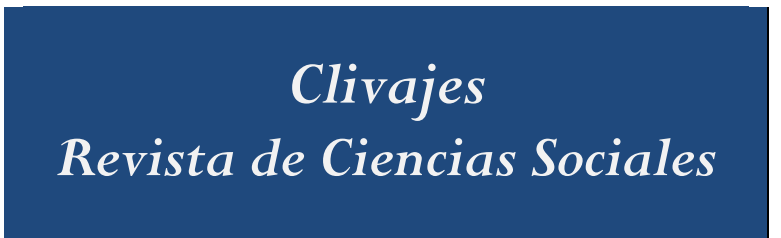

Clivajes. Revista de Ciencias Sociales

ISSN: 2395-9495

http: / / cort.as/-8qzD

IIH-S, UV, México

Mariana Cecilia Fernández

JUVENTUD, RESPONSABILIDAD Y COMUNIDAD

Abordaje Cultural de la Responsabilidad juVEnil en Buenos Aires, Argentina

Clivajes. Revista de Ciencias Sociales. Año V, número 9, enero-junio 2018, pp. 129-152.

Instituto de Investigaciones Histórico-Sociales

Universidad Veracruzana. México

Recibido: 08-12-2017

Aceptado: 10-12-2018

Dictaminado: 16-12-2017

Publicado: 01-01-2018 


\title{
JUVENTUD, RESPONSABILIDAD Y COMUNIDAD. ABORDAJE CULTURAL DE LA RESPONSABILIDAD JUVENIL EN BUENOS AIRES, ARGENTINA
}

\author{
Mariana Cecilia Fernández*
}

\section{Resumen}

Una década, luego de la puesta en marcha de la Ley $\mathrm{N}^{\circ} 13.298$ y su accesoria, Ley $\mathrm{N}^{\circ} 13.634$, que crea el Fuero de Responsabilidad Penal Juvenil en la Provincia de Buenos Aires, es un tiempo considerable que habilita el análisis de la configuración de la trama sociocultural que estructura el ejercicio de medidas no privativas de libertad en instituciones de la provincia de Buenos Aires entre 2015 y la actualidad. Este artículo indaga las matrices culturales que enmarcan los discursos de agentes socio-comunitarios en torno a la responsabilidad juvenil en el marco de la ejecución de tales medidas en la comunidad. Para ello, se emplean técnicas de entrevista en profundidad y se analiza el material desde una perspectiva cultural de la cuestión criminal.

Palabras clave: Responsabilidad, Juventud, Comunidad, Cultura, Medidas no privativas de libertad

\section{INTRODUCCIÓN}

"Yo lo que noto es que podría sistematizarse más lo comunicacional entre los organismos que trabajamos en torno al mismo sujeto: el Centro de Referencia, el Juzgado, el CPA. Si tuviésemos una visión más integral de lo que el pibe necesita, podríamos hacer posible la corresponsabilidad”. Conciso, el testimonio del coordinador de un Centro de Atención Psicosomática (CAP) de la Provincia de Buenos Aires da cuenta de uno de los desafíos más importantes que plantea la implementación de Medidas Alternativas a la Privación de la Libertad (en adelante, MAPL): la construcción de responsabilidad social (“corresponsabilidad"). Medidas puestas en marcha en 2008, en la Provincia de Buenos Aires, a partir de la sanción de la ley $\mathrm{N}^{\circ} 13.298$ de Promoción y Protección Integral de los Derechos del Niño ${ }^{1}$ y su accesoria, la ley $N^{0} 13.634$, que crea el Fuero de Responsabilidad Penal Juvenil y el Fuero de la Familia, con el fin de evitar que jóvenes de 16 y 17 años, transgresores de la ley penal, sean encerrados en instituciones de castigo. Los efectos criminógenos de este tipo de dispositivos son observados por una política pública centrada

\footnotetext{
* Comunicóloga por la Universidad de Buenos Aires (UBA) e investigadora del Instituto de Investigaciones Gino Germani, actualmente es becaria tipo 1 del Consejo Nacional de Investigaciones Científicas y Técnicas (CONICET) y estudiante del doctorado en Ciencias Sociales de la Universidad de Buenos Aires, Argentina.

${ }^{1}$ Esta ley deroga la $\mathrm{N}^{\circ} 10.067$ (que a su vez reproducía la denominada Ley de Patronato $\mathrm{N}^{\circ} 10.903$ ).
} 
en sus derechos y propone su reemplazo por el desarrollo de "medidas socioeducativas" en su comunidad de pertenencia. ${ }^{2}$

En este sentido, este trabajo se propone examinar el modo en que los discursos comunitarios $^{3}$ inscriben las prácticas "socio-educativas" a las que se hallan sujetos los jóvenes, atendiendo en particular el proceso de articulación institucional en función del cual se apunta a intervenir desde distintos ángulos de la cultura en la construcción de responsabilidad social. Si tal como estipula el Decreto 300/05 (que reglamenta la ley $\mathrm{N}^{\circ}$ 13.298 de Promoción y Protección Integral de los derechos del Niño), la corresponsabilidad no es más que un “criterio” tendiente a "sustituir la práctica de la 'derivación' de casos entre instituciones por la construcción de relaciones de corresponsabilidad e interdependencia entre las mismas con el objeto de promover, proteger y restituir derechos en forma integral”, nos interesa examinar el modo en que la legislación se efectiviza (o no) en los discursos comunitarios, es decir, cómo se encarna dicho patrón cultural en los discursos de los agentes que intervienen en la producción de responsabilidad, desde un conjunto heterogéneo de instituciones que trabajan conjuntamente con un Centro de Referencia Penal Juvenil de la Provincia de Buenos Aires. Tomando en cuenta, con Bourdieu y Teuhnc (2000), que el discurso jurídico es capaz de producir efectos en virtud de sí mismo, pero, a la vez, es producido por el mundo social, nos proponemos rastrear las condiciones de producción (Verón, [1988] 2004) de los discursos socio-comunitarios en torno a la "corresponsabilidad".

Las entrevistas con los agentes comunitarios fueron realizadas entre 2015 y 2016 en la Provincia de Buenos aires. Conversamos con tres operadoras socio-comunitarias de un Centro Cultural de la Juventud; la directora de un Centro de Prevención de Adicciones (CPA); el coordinador de un Centro de Asistencia Psicosomática (CAP); el co-coordinador del programa "Construyendo", del CAP; la directora de un Centro Cultural; la responsable del Programa Envión en un Centro comunitario; un coordinador del Programa Jóvenes con Más y Mejor Trabajo; y una voluntaria de una parroquia. ${ }^{4}$ Elegimos estas instituciones porque son las que trabajan con el Centro de Referencia en estudio, en el contexto de una tesis doctoral en curso sobre la configuración de la trama sociocultural que estructura el

\footnotetext{
${ }^{2}$ En tal sentido, el Protocolo para el abordaje de la Responsabilidad Penal Juvenil en la Provincia de Buenos Aires dice: "La primera tarea es evitar que la pena o medida, que regularmente restringe la libertad ambulatoria, vulnere otros derechos (educación, salud, trato digno, vínculos familiares, otros). En este sentido, la accesibilidad a derechos debe ser una labor prioritaria y constante para quienes gestionan, desde sus espacio, las políticas de Responsabilidad Penal Juvenil” (2014: $6)$.

${ }^{3}$ Este trabajo no se centra en el concepto de comunidad; cuando nos referimos a "discursos comunitarios", aludimos a los propios de las instituciones convenidas con el CRPJ, adonde los jóvenes acuden para cumplir la MAPL.

${ }^{4}$ Los nombres de las Organizaciones de la Sociedad Civil fueron modificados para mantener su anonimato.
} 
ejercicio de MAPL, a partir de la articulación de discursos institucionales, discursos comunitarios y discursos juveniles.

Las mencionadas preguntas indagaban, en principio, las características de cada institución o programa; el lapso en que trabajaban con el Centro de Referencia; la cantidad de jóvenes que acudía bajo una MAPL; la conformación de los integrantes del lugar y el modo en que se vinculaban con el CRPJ, para luego centrarse en las estrategias de intervención empleadas; las respectivas matrices de discurso en las que se enmarcaban y la perspectiva institucional en torno a la juventud, la responsabilidad colectiva y la responsabilidad individual.

Como se mencionó anteriormente, el eje de la corresponsabilidad nos suscitaba un interés particular. En este punto, es preciso señalar, con Ortiz Gómez (2014), que el modelo de la corresponsabilidad, centrado en la participación conjunta del Estado, la Organizaciones de la Sociedad Civil (OSC), la familia y la comunidad, pertenece al proyecto cultural neoliberal promovido en campos de política social, trabajo, educación, justicia penal, etc. ${ }^{5}$ Ahora bien, la lógica que se puso en juego, entre 2008 y 2016, durante la implementación de medidas alternativas a la privación de la libertad en nuestro país, si bien se denomina bajo una categoría proveniente de políticas neoliberales de gobierno, en principio, parecería ser distinta. El predominio de un discurso público hacia el joven transgresor, centrado en los derechos humanos, la inclusión y la reforma, así como las políticas públicas en que se basa la intervención de los Centros de Referencia, distan de asemejarse a las nuevas criminologías de la vida cotidiana, nacidas a mediados de la década de los setenta del siglo Xx, que contienen la "teoría de la elección racional", "la "teoría de la actividad rutinaria", el "delito como oportunidad" y la "prevención situacional de la criminalidad" (Garland, 2006); no obstante, también albergan algunos elementos de la táctica social de prevención del delito urbano, la cual, siguiendo a Pat O’ Malley (2006), acentúan el peso del riesgo económico, afectivo y moral que - se considera- lleva al delito, y procuran apartar de la criminalidad a individuos vulnerables, mediante el mejoramiento de sus condiciones de existencia con la asignación de seguros sociales. ${ }^{6}$

\footnotetext{
${ }^{5}$ Si desde el modelo del bienestar el Estado actuaba como regulador de éstos, en la época neoliberal es el ciudadano quien debe mostrarse emprendedor, innovador y competitivo para gestionar sus propias iniciativas de desarrollo, empleo, "reinserción social", etc., asumiendo por sí mismo las responsabilidades que le competen. Organismos municipales, OsC, familias y empresas se ocupan, así, de capacitar y acompañar a los ciudadanos que, con su propio esfuerzo y responsabilidad, llenan los huecos dejados por el Estado.

${ }^{6}$ De hecho, al describir el modelo de la corresponsabilidad, el Art. 2 del Decreto 151/07 especifica: "El sistema de Responsabilidad Penal Juvenil se integra por un conjunto de organismos, entidades y servicios que, en el ámbito provincial y municipal, formularán, coordinarán, orientarán, supervisarán, ejecutarán y controlarán las políticas, programas y medidas destinadas a promover, implementar y coordinar acciones de prevención del delito juvenil, asegurar los derechos y garantías de los jóvenes infractores a la ley penal y generar ámbitos para la ejecución de medidas socioeducativas, centradas en la responsabilidad del joven infractor, posibiliten su real inserción en su comunidad de origen” (El subrayado es mío).
} 
Con todo, la matriz que enmarca el cumplimiento de medidas alternativas a la privación de la libertad resulta difícil de encasillar en un modelo de política criminal. Esto es así, debido a que el sistema de administración de justicia penal juvenil se apoya en organizaciones del Estado y de la sociedad civil que tienen perspectivas heterogéneas. De ahí la importancia del análisis discursivo a través del cual es posible develar la trama cultural en que se instituye la categoría de corresponsabilidad: ¿En qué matriz de discurso se inserta? ¿Qué acciones materializa? ¿El cumplimiento de una MAPL genera distancias entre los miembros de la comunidad?, ¿de qué tipo? ¿Qué disputas se libran? Dedicaremos las siguientes líneas a responder estos interrogantes. El texto se divide en dos partes; en la primera, se analizan las estrategias de inclusión "socioeducativa" y laboral desarrolladas en las instituciones $\mathrm{y}$, en la segunda, se particulariza sobre la concepción y aplicación de la categoría sociojurídica de corresponsabilidad.

\section{EL DEBATE SOBRE LA JUVENTUD, LA RESPONSABILIDAD Y EL CASTIGO}

A lo largo de la historia de las ciencias sociales, el problema de la responsabilidad penal juvenil ha sido estudiado con base en el eje juventud, delito y castigo. Varias investigaciones que lo abordaron en Argentina, desde una perspectiva cultural, coinciden en señalar la incidencia de la sociedad de consumo en la conducta desviada de los jóvenes (Kessler, 2010; Tonkonoff, 2007a y b; Miguez, 2003; entre otros). Si en la época moderna los estándares de juventud se identificaban con un proceso socializador en manos de instituciones familiares, escolares y laborales, en las sociedades tardomodernas los jóvenes son interpelados como consumidores, al interior de un orden social que acabó por quebrar sus hábitos culturales: "en especial por efectos del crecimiento del paro y como consecuencia de un efecto perverso del 'tiempo libre' y la extensión de la adolescencia” (Pegoraro, 2002: 12); de tal modo, no podemos seguir hablando en términos de jóvenes que estudian y trabajan, con las combinaciones posibles, sino más bien en términos de jóvenes consumidores (Tonkonoff, 2016), desafiliados, que, según Tonkonoff, emplean "estrategias juveniles de reproducción" para afrontar cotidianamente sus necesidades y deseos. En sus propios términos, formas de reproducción simbólica y social, que transitoriamente hallan no sólo para sobrevivir sino para ser socialmente jóvenes en el marco de un sistema que los excluye económicamente, pero simbólicamente los etiqueta como "consumidores".

Esta mirada es interesante, porque se despega de los estudios que asocian el delito con la perversidad moral del delincuente a fin de justificar el incremento del castigo, y de aquellos que sostienen una asociación unilineal entre el delito y la pobreza (Miguez, 2003). 
Al respecto, Kessler (2004) subraya que si bien existe una relación entre problemas sociales - pobreza, deserción escolar, desocupación-, y delito, ésta no debe entenderse como una causalidad exclusiva, sino como la matriz de emergencia de un fenómeno. Lo demuestra el incremento de un 150\% de los delitos contra la propiedad, a la par del aumento de la desigualdad y la segregación socioespacial entre 1990 y 2001. Como argumenta el autor en otro trabajo sobre el delito amateur (2010), las actividades ilegales de los jóvenes conviven con su interrumpida permanencia en el mundo laboral; generalmente, no tienen una "proyección profesional" e incluso tienden a disminuir con el transcurso del tiempo.

Si bien no acaban de comprometerse con la delincuencia ni con el mundo laboral, la criminalización concluye el proceso de formación de la identidad de los jóvenes, marcándolos como delincuentes, al tiempo que provoca un efecto contrario a la disminución de los delitos (Tonkonoff, 2007b). Aunque se hallan sujetos a libertades y garantías particulares, los jóvenes se atienen a demandas y castigos diferenciados que persiguen la protección de algunos y exceptúan la de otros (Recepter, 2012). Como sostiene Axat (2013), la justicia penal juvenil es "preferencial”: no persigue a los jóvenes de clase media ni alta, aquellos que se ubican por fuera de los estereotipos construidos en los medios masivos de comunicación y la sociedad en general, y jamás los "prisionaliza".

La selectividad del sistema penal hacia los jóvenes ha sido estudiada, sobre todo desde la perspectiva hegemónica, por la sociología del castigo, el enfoque foucaulteano. En Argentina, este último se halla en trabajos como los de Daroqui et al. (2006), Pasin (2009; 2015), (Guemureman et al. (2010b), Guemureman (2015), Motto (2012) y Ayos (2014), entre otros que indagan la racionalidad del sistema penal, acentuando la gestión diferencial de los ilegalismos ${ }^{7}$ que tiene lugar en la administración de la justicia estatal, la actuación de las fuerzas policiales, la aplicación de políticas públicas de prevención del delito, la intervención institucional en institutos para jóvenes, cárceles, etc.

En relación con el eje de las políticas públicas, Julia Pasin (2009) analiza el Plan Nacional de Prevención del Delito (PNPD) y el Programa Comunidades Vulnerables (PCV), creados en 2001, bajo la idea de que estos programas no constituirían una expresión del populismo punitivo derivado de la implantación del neoliberalismo en occidente, y a nivel regional: "nos encontramos con la construcción de una estrategia de política criminal que presenta a la restitución de derechos (o al desarrollo social, en su versión más

\footnotetext{
${ }^{7}$ Esto es, siguiendo a Tonkonoff (2012a.) el proceso mediante el cual no sólo se castigan las acciones que el derecho tipificó previamente como delitos y se toleran aquellas que han sido permitidas, sino que se produce una cierta clase de delincuentes, aquellos que ejecutan los ilegalismos no tolerados (los sectores populares), para diferenciarlos de otros infractores, aquellos que cometen los ilegalismos tolerados (los sectores de poder). Una vez que se establece qué bienes jurídicos preservar, el derecho, las fuerzas policiales y el sistema penal proceden con cierta autonomía respecto de la sanción legal, descubriéndose como piezas de un engranaje mayor tendiente a separar los ilegalismos de la delincuencia.
} 
contemporánea) como parte impescindible de su desarrollo” (2015: 16). En este mismo sentido, afirma Ayos (2014) en un trabajo basado en su investigación doctoral, la principal dificultad de este tipo de programas es no trazar una línea clara entre el campo de las políticas sociales y el campo de la política criminal:

Las implicancias políticas de esta superposición de campos son trascendentes, puesto que al ponerse en práctica estos planes, es probable que la política criminal reencuentre a estos sujetos como objetos de una política social cuya finalidad no los incluye, pues consiste en aumentar la seguridad de otros ciudadanos" (p. 9).

En línea con ello, subraya Oyhandy $(2004,2006)$ en sus trabajos sobre las prácticas y discursos mediante las cuales se protege a niños y adolescentes en riesgo, la definición de una situación "de riesgo" involucra valoraciones morales y políticas naturalizadas por los jueces de menores en función del riesgo para la sociedad que suponen que produce el niño o adolescente.

De las prácticas de los agentes de la justicia de menores en tribunales orales de Buenos Aires se ocupa la tesis doctoral de Guemureman (2008). La autora subraya que en un escenario signado por la inseguridad ciudadana, atribuida mayormente a los jóvenes, las decisiones de los jueces varían en torno a las medidas restrictivas de la libertad, debido a la instalación en la agenda pública del discurso de derechos, agenda que admite la pena de privación de la libertad como medio de última ratio; la apelación a dicha disposición, en casos extremos; la deslegitimación de la pena en su función resocializadora; la falta de vacantes en instituciones de encierro; la relevancia del fallo de la Comisión Interamericana de Derechos Humanos (CIDH) por el caso Bulacio y la sucesión de episodios de violencia institucional en comisarías bonaerenses. En última instancia, dice, los jueces apelan a la racionalidad del sistema jurídico, a fin de hacer más previsible la aplicación de la norma, pero mantienen la racionalidad estructural del orden vigente. A ello se suma que, en casos de gran impacto, no emplean la pena que consideran justa, sino la que creen que demanda la ciudadanía.

En relación con la sanción de la Ley de Responsabilidad Penal Juvenil N ${ }^{\circ} 13.634$, la tesis de maestría de Ana Laura López (2010a) reconstruye el contexto de producción de la ley, y señala que el proceso de reforma se bifurcó entre quienes se opusieron a la derogación del régimen de Patronato de Menores, los "defensivos" (compuesto en un primer momento por los poderes judicial y legislativo, sectores de los gremios estatales e intendentes provinciales) y quienes promovieron activamente su reemplazo por un sistema afín al modelo de la Comisión CDN, los "ofensivos". El discurso de los derechos del niño sufrió un proceso de fetichización, señala la autora, cuando al sector “ofensivo”, compuesto 
en un primer momento principalmente por sectores universitarios y técnicos, se incorporaron movimientos sociales por los derechos del niño e intendentes provinciales, sumado al activismo de los organismos internacionales y el consentimiento académico sobre el despropósito de mantener el modelo del patronato. Luego de la sanción de la ley 13.298, el proceso de ejecución del modelo de los derechos conlleva un efecto de desilusión para el sector "ofensivo", que reconoce una reapropiación retórica de las categorías propias del nuevo paradigma a las prácticas vigentes durante el modelo del patronato.

Un estudio sobre la implementación de medidas socioeducativas en el marco del Sistema de Responsabilidad Penal Juvenil (SRPJ) es el de Ocampo (2016), centrado en el Centro de Recepción, Evaluación y Ubicación (CREU) de Lomas de Zamora. La tesis señala la invisibilización, desinterés e indiferencia existente al interior de instancias decisorias de los espacios que albergan a los jóvenes, así como del SRPJ, en general, cuyos efectos se materializan en cuestiones como la falta de insumos, la violación de los tiempos estipulados en la Convención de los Derechos del Niño para el procesamiento del joven; la escasa atención de sus defensores; la deficiente atención en salud; la carencia de tratamiento en adicciones, además de pocas horas de escuela, maltrato de los asistentes de minoridad hacia los jóvenes, entre otras.

Un estudio más, sobre la implementación del nuevo Sistema de Responsabilidad Penal Juvenil, es de Julián Axat (2014): Aportes críticos sobre los proyectos penales juveniles para Santa $F$ e, en el cual detalla algunos de los problemas que surgieron en la ejecución del nuevo sistema de justicia: 1) incremento de las tasas de encierro; 2) adultización de los criterios penales jurisprudenciales; 3) predominio y fortificación de las ingenierías punitivas (Ley Penal Juvenil) y extenuación y desinversión en ingenierías de promoción y protección de derechos e instrumentos de salud mental; 4) hacinamientos carcelarios y modificación de los dispositivos de encierro, como sitios de depósito-confinamiento; 5) problema de la policía y la captación-selectividad y certificación judicial de la criminalización de la pobreza juvenil; 6) la facultad de la reforma de limitar y neutralizar lo máximo posible (aun siendo el techo de las imprudencias que habilita el dec. 22.278). De ahí la pregunta por el modo en que un sistema procesal ideado como de 'mínima intervención punitiva' acabó por producir mayores clientelas de jóvenes en lugares de encierro que el sistema anterior a 2008, o acaso mayor coacción punitiva sobre jóvenes pertenecientes a los sectores populares: “¿Redefinió nuevas etiquetas de apariencia progresista, para en realidad, dar aval de legitimidad a un control social sutil y específico de los excedentes poblacionales?” (p. 3). 
En relación con el problema de la "adultización de los criterios penales jurisprudenciales”, López Gallego y Padilla (2013) subrayan que en el Sistema de Responsabilidad Penal Juvenil uruguayo, ${ }^{8}$ si bien se pretende apartar las intenciones del actor del hecho ocasionado, se produce una tensión entre la doctrina de la Protección Integral y la doctrina de la Situación Irregular, que a veces habilita intervenciones garantes de derechos y otras da lugar a sinsentidos que vuelven ineficaz y restrictiva la noción de responsabilidad.

Esto no significa que deba procederse derivando la imputación de un delito, automáticamente, de una supuesta situación donde el joven tendría un derecho amenazado, señala Beloff (2002). En tal sentido, la autora propone analizar cada situación en particular, asumiendo que la nueva justicia juvenil no apunta a 'hacer el bien' al joven acusado de cometer un delito, sino a provocarle un sufrimiento mínimo. Si la intervención de la justicia impacta positivamente en el joven, éste es un valor adicional, pero no el principio en que se funda.

$\mathrm{Al}$ respecto, advierte Uriarte (2013) en Los sentidos del castigo. El debate uruguayo sobre la responsabilidad en la infracción adolescente, la exigua orientación al reproche penal que suele predominar en la implementación de la Justicia Penal Juvenil se vincula con una perspectiva aproblemática sobre la selectividad del sistema penal y judicial hacia su clientela principal: el joven pobre.

Por su parte y con respecto a los problemas en la implementación del modelo de justicia basada en los derechos, Pitch (2003) señala dos dificultades principales; por un lado, asimilar los conceptos de responsabilidad, responsabilidad penal e inimputabilidad, así como los mecanismos de imputación hechos por el tribunal y los procedimientos sociales y políticos de responsabilización. Esto significa que el castigo penal tiene el fin de responsabilizar al ofensor, con lo cual, aunque la pena dependa de la acción y no de las propiedades del sujeto, mantiene la finalidad de influir en su personalidad mediante una pedagogía moralizante; por otro lado -indica la autora-, es preciso tener en cuenta que si bien la familia, la escuela, los servicios sociales son agencias de control social, sólo al sistema de justicia penal le compete la imposición de sanciones por la fuerza. Por su parte, el sistema socioasistencial (que también lo es) puede ejercer su función, permitiendo al sujeto participar voluntariamente de las intervenciones $\mathrm{y}$, de ese modo, impedir que se justifique, en términos de "garantías" y "responsabilización”, una mayor extensión del control social penal mediante la reinvención del papel pedagógico de la pena.

\footnotetext{
${ }^{8}$ La mayoría de los países de la región latinoamericana han efectuado la reforma del Régimen Penal de la Minoridad, sugerida por la Convención Internacional de los Derechos del Niño (CIDN) y creado nuevos sistemas para regular la condición jurídica de la infancia y la adolescencia, salvo México, Chile y Argentina (Beloff, 2002).
} 
En torno al problema de "corregir castigando" o "castigar corrigiendo" (Di Giorgi, 2005: 38), podemos mencionar un trabajo de Zaffaroni (1998) que caracteriza al sistema penal como "control social punitivito institucionalizado" y lo distingue del sistema penal propiamente dicho, frente a sistemas penales paralelos. El primero se halla compuesto por leyes penales, agencias de seguridad y control social, tribunales, cárceles, institutos, etc., que reconocen explícitamente su carácter punitivo; y el segundo, se constituye de discursos no punitivos tales como el terapéutico o tutelar, que legitiman al sistema penal manifiestamente punitivo.

Por su parte, los únicos estudios sobre dispositivos abocados al cumplimiento de penas alternativas a la privación de la libertad son los de López et al. (2009), que indaga su materialización en la Provincia de Buenos Aires, la Ciudad de Buenos Aires, Río Negro, Santa Fe, Mendoza, Córdoba y Tucumán; la tesis de maestría de Lucesole (2012), que estudia el Centro de Referencia de la ciudad de La Plata; la tesis de licenciatura de Nicoletti (2014), quien también realiza un estudio de caso sobre el Centro de Referencia de La Plata; y la de María Alejandra González (2015), sobre la implementación de medidas alternativas a la privación de la libertad en el Centro de Referencia de Tandil.

Vemos, entonces, la vacancia presente en el estudio de medidas alternativas a la privación de la libertad. Este trabajo busca aportar al conocimiento de este tipo de intervención penal juvenil, desde una perspectiva atenta no sólo a la racionalidad política del sistema de administración penal de justicia y sus mecanismos de gestión diferencial de los ilegalismos, sino, ante todo, al sentido que los agentes comunitarios que lo constituyen dan a la categoría sociojurídica de corresponsabilidad. Creemos que es allí, en el sentido socialmente atribuido a los conceptos estructurantes de la penalidad juvenil, que atañe a las medidas alternativas a la privación de la libertad, donde reside la explicación por los "fracasos", en términos foucaulteanos, del sistema de administración estatal de justicia. Las "fallas" de tal sistema no remiten solamente al funcionamiento de una tecnología política, sino a la incidencia de fuerzas legales y culturales de legitimación y resistencia (Garland, 1999).

\section{Exclusión educativa, responsabilidad laboral y esquina}

Las estrategias de intervención de los agentes comunitarios se fundan en la palabra. La acción performativa que sus discursos ejercen sobre los jóvenes intervenidos impone una forma legítima de concebir la responsabilidad que se instituye durante prácticas institucionales y se sanciona colectivamente en la comunidad. Lo hace sólo, y en la medida en que se asienta en actos de autoridad pronunciados por "referentes" depositarios de una facultad delegada: la de supervisar el cumplimiento de MAPL e informar al Centro de 
Referencia el proceso realizado por cada joven en un período de tiempo concreto. Para que ello sea posible, los jóvenes deben ser incluidos en la escuela, programas sociales y/o instituciones de la comunidad desde donde "responsabilizarse" durante el transcurso del proceso judicial. Ahora bien, de acuerdo con el trabajo de campo realizado, no podemos decir que la expulsión institucional que soporta el joven antes de la apertura de la causa judicial logre revertirse en el transcurso de ésta. Como señalan López et al. (2009b), son pocas las instituciones de la sociedad civil que permiten el ingreso de jóvenes con causas penales, lo cual, sumado a la escasez de espacios dedicados al área de niñez y adolescencia, genera inconvenientes para los agentes comunitarios que deben insertarlos "en algún lado".

Este problema se le presenta al coordinador de un Centro de Atención de Enfermedades Psicosomáticas (CAP), un dispositivo que realiza talleres de expresión y tratamientos de psicoterapia con el joven y con su familia, "derivados" tanto de Centros de Referencia (si tienen 16 y 17 años, y se hallan bajo una MAPL), como de Servicios Zonales (si tienen entre 14 y 16 años, y se hallan en "condición de vulnerabilidad social"), lo cual confirma la idea planteada por las mencionadas autoras, de que las MAPL suelen ser utilizadas para jóvenes infractores no punibles, en razón de la falta de políticas sociales dirigidas a dicho grupo poblacional.

Así se refería el responsable del CAP a la "lógica de artesanato" (González, 2015: 99) que debe implementar para incorporar a jóvenes que se hallan bajo una MAPL a planes, instituciones, programas o becas, muchas veces sin éxito:

Si tienen entre 16 y 18 tratamos de que se inserten en el plan fines o en cualquier colegio que los acepte. En general, no los aceptan. No es tan fácil, siempre encuentran alguna excusa. También nos cuesta conseguirles becas para que hagan cursos de carpintería, tornería o lo que sea. Acá en el municipio supuestamente hay pero las vacantes no llegan: ¿sabés las veces que pedimos? Siempre están llenos, no sé qué, por esto, por lo otro, nunca está la vacante.

El CAP trabaja con jóvenes del CRPJ desde una perspectiva de derechos. Se aboca al desarrollo de talleres de orientación vocacional, elaboración de currículum y talleres de expresión audiovisual, donde a partir de la observación colectiva de una película sobre distintos temas, y particularmente el laboral, se trata de propiciar que los jóvenes se pregunten "qué les gustaría ser", se visualicen en algún área donde les gustaría estar, se identifiquen con el rol de algún personaje, desechen espacios donde no trabajarían, etc. Un enfoque similar al propiciado en el programa Jóvenes con Más y Mejor Trabajo (JMMT), que si bien se dirige a jóvenes de 18 años en adelante, el CRPJ deriva a aquellos que han cumplido la mayoría de edad y aún no concluyeron la medida, así como también, en casos 
excepcionales, a jóvenes de 17 años a los que se les otorga un permiso especial para que puedan participar.

El tipo de responsabilidad que se fomenta a través de este programa -sostiene el entrevistado- es una de las más significativas en cuanto a la transición del mundo de la adolescencia al de la adultez, pues el hecho de estar empleado supone la internalización de rutinas, reglas, horarios; la construcción de un perfil laboral y la asunción de las consecuencias de las propias acciones.

El Jóvenes es un programa dedicado a sectores que no sólo no tienen garantizado el derecho al trabajo sino que no tienen cultura del trabajo, están en la esquina: ¿qué hacemos?, ¿cómo nos acercamos? Vamos al barrio y territorializamos el programa. Y lo que vemos cuando llegamos es la relación del estado con los pibes, instituciones educativas que terminan siendo expulsivas y entonces aparece el brazo represivo.

Al igual que en el discurso del coordinador del CAP, en este enunciado aparece el problema del carácter expulsivo de las instituciones educativas; carácter que remarcaron, en general, todos los entrevistados, desde la voluntaria de una parroquia, que señaló: "Acá, en esta zona, la secundaria es un desastre, abandonan mucho", hasta la coordinadora del programa Envión, quien subrayó que: "la realidad es que las escuelas son bastante expulsivas, hay algunas que trabajan un poco mejor, pero en la mayoría si el pibe molesta, “chau sacámelo de encima'”. La escuela aparece en términos de lo que Duschatzky (1996) denomina "frontera"; esto es, como el borde que separa a jóvenes de sectores populares de aquel mundo constituido por lenguajes y soportes a los que no acceden e incluso varios no conciben en el marco de sus expectativas, pues las problemáticas sociales que soportan ocupan el centro de sus preocupaciones.

Este proceso de exclusión, por el cual el joven deja de ir a la escuela, se asocia al hecho de que comience a reunirse en la esquina y a que la expulsión educativa no se intente afrontar con políticas sociales, sino con el "brazo represivo del Estado". La esquina, como "respuesta obligada de una condición no deseada que lo lleva a ver transcurrir el tiempo en espacios reiterados y estables" (Duschatzky, 1996: 18), es un sitio en el que se apunta a intervenir, por un lado, mediante la revinculación en alguna institución escolar que los reciba y, por otro, iniciándolos en la “cultura del trabajo”, arrebatada durante la década de los noventa, a través de cursos, talleres, programas de empleo, etc. En relación con el trabajo - cuenta el coordinador de JMMT-, ocurre algo similar a la imposibilidad de imaginarse en la escuela, cuando los jóvenes de sectores populares se prefiguran en oficios o actividades no calificadas, sin verse en la universidad y puestos de trabajos calificados: 
Es muy loco: nosotros hacemos un ejercicio que tiene que ver con preguntar de qué te gustaría trabajar y en las clases más altas aparecen trabajo vinculados a profesiones universitarias, en cambio, en los sectores populares aparece chofer de camión, repositor, vendedor. Y eso está vinculado a lo que veo en mi entorno y así se va construyendo ese imaginario de lo posible.

El modo de vincularse y concebir los jóvenes al trabajo no se halla desligado de su paso por la escuela, pues, como sustenta Tenti Fanfani: "allí no solo se aprenden las capacidades expresivas básicas, sino que también se desarrollan valores, actitudes y esquemas de comportamiento que estructuran las prácticas futuras de los aprendices” (1993: 3). La educación secundaria moldea las expectativas laborales de los jóvenes y deja huellas en sus personalidades, las cuales traen aparejada diferencias simbólicas que concuerdan con la estratificación de las alternativas de empleo. "En este sentido, la escuela como frontera es la escuela portadora de variación simbólica, es decir, la escuela que introduce una diferencia" (Duschatzky, 1996: 18).

En este punto, podemos vislumbrar dos modos distintos de encarar el problema entre las instituciones de la comunidad: la primera da cuenta de la importancia de intervenir desde el territorio para interpelar a los jóvenes, y la segunda, al contrario, tiene como finalidad distinguirse de él. Veamos un ejemplo de cada una de estas estrategias:

Las instituciones tienen que abrirse. Si el pibe está faltando, acércate a la casa, jsi sabes la dirección! Porque la familia para ir a anotarse se acercó, entonces, si falta acércate vos como institución a ver qué está pasando que no viene (Operadora del Centro Cultural de la Juventud).

- En general, tratamos de transmitir que esto es un espacio para ir construyendo la confianza entre ellos y nosotros y que la forma es a través del hablar y que tienen toda la libertad para decir qué les gusta y qué no, pero siempre con respeto. Tratamos de diferenciarnos de la calle.

\section{- ¿Cómo hacen eso?}

- Cuando vienen y hablan con una expresión que no conocemos, le preguntamos "iqué es eso?” y los corregimos, con todo respeto, le decimos "eso se dice así, entonces, la próxima vez referite de esta forma" (Directora del CPA).

Las estrategias exhibidas son, evidentemente, distintas. La primera se basa en el acercamiento, la muestra de interés y la insistencia por parte de "la institución" hacia el joven, a quien se intenta convocar a la participación de todas las maneras posibles para conseguir que asista; la segunda, en cambio, erige las diferencias entre nosotros y ellos en el uso del lenguaje. El respeto se manifiesta en la utilización "correcta" de las formas de hablar y expresarse durante las entrevistas por parte de los jóvenes, a quienes, ante el empleo de una palabra desconocida por el agente socio-comunitario, se impone la categoría legítima. 
Esto es así, según Alabarces et al. (2008), porque la posición de subalternidad que define a los jóvenes les impide producir discursos legítimos sobre sus propias prácticas, frente a los poderosos, que marcan los límites de lo enunciable en el marco de la cultura hegemónica; de otra manera, dejarían de ser subalternos y perderían su condición de objeto. Lo que brota en aquellas marcas de estilo, propias de la cultura subalterna, desconocidas por la directora del CPA son los códigos y prácticas populares que quiebran el entramado de las voces legítimas y certifican que lo popular se halla en el margen de lo hegemónico.

Si bien desde el CPA se intenta "ir construyendo la confianza entre ellos y nosotros" a través del diálogo, y se pretende darles “toda la libertad para decir qué les gusta y qué no”, al pedir a los jóvenes que empleen el término "correcto", entendemos, con Hall (1984), que lo que se hace es descontextualizar el elemento cultural puesto en juego en el habla, y esa inserción contextual distinta no puede más que obstaculizar la comprensión de la concepción del joven sobre lo que cuenta, otorgándole otra resonancia. Precisamente, como los códigos no son fijos, sino estructurados en torno a las tendencias y oposiciones entre lo correspondiente a la cultura hegemónica y lo correspondiente a la cultura periférica, varían e incluso "tienden a cruzarse y a coincidir en el mismo campo de lucha" (p. 10).

Vemos, así, el modo en que opera la disputa hegemónica y se define en cada práctica discursiva, mediante el trazado de la frontera entre lo que se debe incorporar y lo que se debe excluir de la cultura legítima de una época; una frontera discursiva que permite diferenciar el espacio institucional de "la calle", con base en los valores y principios que instituye el lenguaje, como resultado de una disputa por el sentido legítimo de los significantes.

\section{2. ¿Responsabilidades compartidas?}

Teniendo en cuenta la heterogeneidad de las instituciones que definen la estrategia de responsabilidad, surge la pregunta por su integralidad, una de las características centrales postuladas por el modelo de corresponsabilidad. ${ }^{9}$ La efectividad de este último reside, en primer lugar, en el mantenimiento de una comunicación fluida entre los actores que intervienen en el diseño de la estrategia. Si bien el informe que se envía al juez, donde se comunica el proceso desarrollado por cada joven en el marco del cumplimiento de la medida, es elaborado mensualmente por el equipo técnico del CRPJ, los responsables de las instituciones que trabajan en forma descentralizada con éstos deben comunicarse para

\footnotetext{
${ }^{9}$ De acuerdo con el Decreto 300/05 (que reglamenta la ley 13.298), la categoría de corresponsabilidad debe entenderse como un "criterio" tendiente a "sustituir la práctica de la 'derivación' de casos entre instituciones por la construcción de relaciones de corresponsabilidad e interdependencia entre las mismas con el objeto de promover, proteger y restituir derechos en forma integral".
} 
informar el desempeño que han mantenido hasta entonces, y si se considera pertinente seguir en la misma línea de trabajo o darle otro encuadre a la estrategia.

Como señalan las operadoras del Centro Cultural de la Juventud, el “acompañamiento" conjunto entre los agentes del CRPJ y los agentes socio-comunitarios permite superar resistencias por parte del joven a participar de las entrevistas, así como también a transmitirle confianza y consideración por sus preocupaciones, incertidumbres y preferencias:

Esto de trabajar más integralmente es bueno, porque al Centro de Referencia le cuesta trabajar en el territorio y nosotros ya tenemos la mirada bastante hacia los jóvenes, eso los aliviana. O sea, es mutuo, si el pibe no quiere ir solo a la entrevista nosotros lo acompañamos y si el pibe no quiere ir al Cetro de Referencia y quiere tener la entrevista acá vienen desde el Centro de Referencia y la hacen acá. Para que se sientan más seguros, al menos en el primer contacto, después irán solos.

Vemos aquí que al trasladarse los agentes del CRPJ a un espacio socio-comunitario, el carácter de la entrevista se modifica. El contexto en el que se realiza promueve una sensibilidad distinta en el CRPJ, que habitualmente atemoriza a los jóvenes debido al carácter obligatorio de la cita; una sensibilidad que podríamos concebir como más comprometida con los jóvenes, por ser éste un ámbito conocido por ellos; de modo que acceden a participar, porque confían en las operadoras que los acompañan. En este caso, la inclusión socio-comunitaria de la MAPL sortea el riesgo de convertirse en una "modalidad burocrático-punitiva" (Lucesole, 2012: 145), pues no depende de la mera voluntad del joven para cumplirla. Veamos el caso de los jóvenes que asisten al programa JMMT:

Nosotros hacemos el seguimiento de la persona que en la oficina se referencia con alguien. Eso lo hace el equipo de orientación, se crea un vínculo y eso posibilita la intervención. Hay acciones que descansan en el vínculo que construye ese referente del equipo y la persona que está participando. Pero después, es uno más. No se lo identifica como "éste es el que viene de tal lugar". En los casos en los que el Centro de Referencia nos llama y quiere articular, nosotros articulamos pero por lo general no pasa eso.

La creación de un vínculo entre el joven y un "referente" emerge en el discurso como facilitador de la intervención; sin embargo, en este caso, la articulación con el CRPJ no se produce. En este punto, hay que señalar que son muy pocos los jóvenes derivados al programa JMMT e informados de su existencia, principalmente en razón de la edad, y que los que llegan no son acompañados por los operadores del CRPJ, sino informados por ellos sobre de qué se trata el programa. Este procedimiento tiene la ventaja de permitir que no se lo identifique como "el que viene de tal lugar", y la desventaja de la carencia de vinculación entre instituciones. En el caso de que el joven asista por motivación propia o 
por acompañamiento de algún familiar o amigo ajeno al CRPJ, solicita las constancias que certifican su participación en el programa para llevar al CRPJ, y la relación que construye con el "referente" comunitario se establece con relativa independencia del cumplimiento de la medida.

En este caso, la desarticulación se ve compensada por la perspectiva de derechos que mantiene la política pública, impidiendo que afecte al joven que cumple la medida en los términos esperados (asistencia regular a las capacitaciones, llegada puntual en el horario establecido, etc.), pero en el caso de los jóvenes que no logran sostenerla, la falta de comunicación entre los equipos técnicos, del programa y del CRPJ, impide intervenir en la deserción. Lo mismo ocurre en la parroquia, donde la comunicación con el CRPJ es poco habitual y, a diferencia del programa JMMT, no posee una perspectiva de derechos.

Mucho no llaman para ver cómo les está yendo, de eso me ocupo yo, de decirles "vení tal día a tal hora, cumplí con lo que te dijeron y ya está". El vínculo lo genero yo porque no sé cuál es la historia que trae y por lo general tengo una relación muy maternal: los recibo hablándoles de que se les va a dar la oportunidad, me gusta hablar con ellos. Después los encuentro en algún lugar y me agradecen, los veo y me abrazan. Porque son chicos del barrio que tienen hijos, consiguen un trabajo y siguen su vida.

Pese a la desconexión entre el CRPJ y la parroquia, el discurso en torno a la oportunidad (ante la ley y ante Dios) otorgada al joven se erige en una recurrencia. Lo que subyace en este discurso (del Estado y de la iglesia) es el perdón, como figura de orden moral y remisión (de la pena). Ahora bien, ¿contribuye esta coincidencia a la integralidad de la estrategia de responsabilidad? ¿El contexto religioso en el que se desarrolla la tarea comunitaria conlleva la reproducción de la responsabilidad asumida por fuera de la parroquia? Considerando que en general el joven es detenido por primera vez y la experiencia delictiva suele ser una circunstancia en su vida, podemos decir que la tarea desarrollada en la parroquia es un "rito de paso" (Leach, 1993) que, con el tiempo, también resulta anecdótico. ¿Qué queda, entonces, de dicha experiencia? El vínculo con la referente de la parroquia, conocida previamente a la asignación de la medida. Ese vínculo se halla cargado de afecto sincero y se mantiene debido a la pertenencia territorial de ambos.

Sin embargo, la estrategia no es integral. Al igual que en el caso del programa JMMT, si el joven no acude, el CRPJ se entera sólo por el hecho de no recibir las constancias de la realización de las tareas comunitarias, pero no lo "acompaña” de ninguna manera. A diferencia de ello, en instituciones como el CPA, el CAP, el Centro Cultural de la Juventud, el centro comunitario donde radica el programa Envión, se sistematiza por escrito, telefónicamente y en reuniones cara a cara el modo en que el joven se encuentra 
cumpliendo la medida: si asiste, si falta, si se siente cómodo, si hubo algún conflicto, etc. Se entiende que es necesario mejorar esta articulación, a fin de relacionarse con el joven de manera más profunda y lograr comprenderlo:

Nosotras hablamos con los compañeros del CRPJ por teléfono para verificar si el pibe que está viniendo acá está yendo allá y ver la situación en la que anda el pibe o por ahí ellos llaman para decirnos "che, mirá, vino tal pibe" (Operadora del Centro Cultural de la Juventud).

— ¿Cuál es el mayor impedimento en el seguimiento?

- La asistencia continua. A veces no vienen porque encontraron un trabajo y venir acá implica no cobrar. $O$ sea, que no vienen porque están mejorando. Otras veces no vienen porque están empeorando (Cocoordinador del CAP).

- Hay pibes que no vienen porque no les interesa, no saben con lo que se van a encontrar. A lo mejor piensan que se van a encontrar con personas que les hablan y les dicen "vos no tenés que consumir, vos tenés que cuidarte", viste, que le bajan la línea.

- ¿Hay gente así?

- Sí, y también hay otros que le tiran otra: "vos tené cuidado, yo ya la vivi", depende de cómo es el compañero que se hace cargo. Lo que nosotros hacemos es un encuentro de capacitación con todos los compañeros y de a poquito entre todos vas generando algo más abierto, más de reflexión y no solo que hagan la probation y listo. Este año tuvimos 7 pibes y uno se queda con la sensación de que lo que les falta es contención (Directora del Centro Cultural).

Es paradójico -y los propios entrevistados lo señalan- que cuando el joven "está mejorando" (debido a que encontró trabajo), a veces la medida debe extenderse más de la cuenta, pues éste no acude a realizar el trabajo comunitario que judicialmente se le indica. $\mathrm{Si}$ la finalidad de las tareas comunitarias fuese la misma que la de trabajar, podría sustituirse una cosa por la otra, pero ello no sucede debido a que el fin de la segunda se centra en la reparación el daño y no en responsabilizar al joven en el sentido que proponen el programa JMMT, los talleres del CAP, etc., es decir, en la dimensión laboral y socioeducativa. Si bien habitualmente esa última calificación "socio-educativa" ha resultado un eufemismo tendiente a justificar la intervención socio-penal en el encierro y los efectos de incapacitación selectiva que la pena privativa de libertad genera a jóvenes alojados en cárceles (Guemureman et. al, 2010) e institutos de menores, en tanto eslabones del continuum institucional criminalizante (Alfieri y Olmos, 2011), entendemos que, en el marco de la ejecución de medidas alternativas a la privación de la libertad en instituciones comunitarias con perspectiva de derechos, la adjetivación como "socio-educativas" adopta 
un sentido pedagógico y moral vinculado a la restitución de derechos, el autovalimiento y la responsabilidad.

Mientras en instituciones que no poseen una perspectiva de derechos, como el Centro Cultural o la parroquia, emergen discursos formulados en términos protectorios y paternalistas, de acuerdo con valores como contener, ayudar y educar, correspondientes a la matiz del patronato (García Méndez y Vitale, 2009), ${ }^{10}$ así como las nociones de "falta de escrúpulos" y “contención familiar" que, desde la implantación - a principios del Siglo XIXde la Ley de Patronato de Menores No 10.903 - conocida como Ley Agote- y la "Doctrina de la situación irregular", alimentaron una tendencia a concebir al joven pobre como naturalmente inclinado hacia la delincuencia (Daroqui y Guemureman, 1999), en el resto de las instituciones analizadas (la Casa de la Juventud, el centro comunitario de Hurlingham, etc.) son más recurrentes significantes tales como el de "autovalimiento", “acompañamiento" y “corresponsabilidad”. Y si, no obstante, en ocasiones aparecen algunos de los significantes antedichos (sobre todo el de ayuda), al insertarse en la matriz de los derechos del joven, su sentido se modifica. Lo cual no debe hacernos perder de vista que al interior de cada institución existe una diversidad de actores cuyas trayectorias son tan heterogéneas, que si bien conforman un espacio en común, no siempre reproducen un discurso homogéneo. Veamos algunos ejemplos:

\section{- La finalidad de la intervención, ¿cuál es?}

- El autovalimiento: la propia valoración de sí mismo, la reestructuración de los lazos sociales, porque uno recibe un emergente, pero esto es un problema social (Coordinador del CAP).

- En realidad, lo que uno les tiene que transmitir es que puedan ver el lado positivo de la vida, las cosas que pueden disfrutar, las cosas que pueden hacer; que empiecen a confiar en sus capacidades, que puedan ver sus potencialidades, que puedan ver que pueden. Me parece que tiene que ver con eso, con el autovalimiento. Que sepan que pueden darle para adelante, que puedan proyectarse pero que puedan también cambiar de proyecto (Coordinadora del programa Envión)-

El significante de autovalimiento no aparece en los discursos como opuesto al de coresponsabilidad, sino como complementario: la "propia valoración de sí mismo" permitiría al joven avanzar con convicción hacia "lo que se propone", esto es, hacia un "proyecto de vida" construido "más allá de las circunstancias" y junto a "gente que puede ir acompañando estos procesos”. Resalta aquí el aspecto volitivo y actitudinal del joven para proyectar su vida por fuera del delito, frente a factores estructurales que enmarcan su

${ }^{10}$ Se llama "Sistema de Patronato" al proceso inaugurado en 1938, con la sanción de la ley 4.66, que habilita el denominado "proceso irregular": "un proceso institucional que materializa una cultura según la cual la política social para los hijos de los pobres será competencia exclusiva y excluyente del poder judicial” (García Méndez y Vitale, 2009). 
relación con este último. La condición de clase no aparece en los discursos como condicionante de la posición desde la cual los jóvenes deciden alejarse del delito, pues, como subrayan los discursos, este proyecto debe implicar un cambio: "que puedan proyectarse pero que puedan también cambiar de proyecto".

Ahora bien, en tanto expresión visible de un proyecto desviado, el delito se construye como un problema no sólo del joven, sino del conjunto de los miembros de la sociedad, entre quienes el lazo social se hallaría quebrado, y sería necesario reestructurar "el emergente de un problema social", mediante autovalimiento y acompañamiento. Los agentes comunitarios conciben a los jóvenes como sujetos capaces de "hacer cosas", "ver el lado positivo de la vida", “alcanzar sus sueños", valorarse a sí mismos y a los demás; piensan que si no lo hacen es porque "están en conflicto con el proyecto de vida", pero no porque no lo puedan lograr. Se trataría, entonces, de reforzar los vínculos sociales y las relaciones de reciprocidad, desde la familia hasta las instituciones de la comunidad, a fin de contribuir a que el joven pueda "potenciar" sus capacidades con respeto y responsabilidad hacia sí mismo y hacia los demás.

En tal sentido, creemos que la mayor diferencia que aporta el régimen de derechos, en el plano cultural, por sobre el régimen tutelar, remite al acompañamiento ambulatorio que sucede al juicio oral, el cual apunta a que los jóvenes sientan que valen para alguien y, en consecuencia, se apoyen en los agentes comunitarios para cambiar sus hábitos vinculados a la transgresión. Del mismo modo, estos últimos se proponen generar una referencia del joven con el espacio institucional, para que advierta que cuando quiera puede acudir a él, y cuando no, dejar de participar.

De acuerdo con los discursos relevados, el proceso de referenciación es importante, ante todo, porque es lo único que puede evitar el encierro de los jóvenes (ya sea en una institución penal o en una comunidad terapéutica). Si bien, en términos del coordinador del CAP, "el pibe que tiene un acompañamiento firme de la familia no son este tipo de población" y, en palabras de la directora del CPA, la "falta de red familiar es lo que impide sostener la medida", el referente comunitario adopta un papel de "acompañante" o "facilitador" que viene a sustituir el rol (“ausente") de la familia.

En contraste con los discursos de los agentes comunitarios (y también, de los del CRPJ), Kessler (2010: 149) ha conjeturado una "sobreimputación de las causas del delito a la familia”, que responde a perspectivas ideológicas conservadoras presentes no sólo en las investigaciones criminológicas contemporáneas, sino en el sentido común elaborado en los medios de comunicación masiva; idea que predomina entre los discursos de los entrevistados. Sin embargo, afirma el autor, la incidencia del factor parental se modifica de conforme al tipo de delito del que se trate y, además, al hecho de que los progenitores se 
encuentren divorciados o haya muerto alguno de ellos; por sexo, nivel socioeconómico y edad: "El consenso actual es que solo en interacción con otros factores, determinados contextos familiares constituyen contextos donde es más probable que desarrollen actividades delictivas" (2010: 150).

La interrelación de cada uno de los elementos antedichos es, entonces, lo que puede generar condiciones favorables a la acción delictiva. El joven que delinque no se halla determinado por la cultura parental (Miller, 1958), sino que es un actor transitoriamente carente de autocontrol que en ciertas condiciones, imperceptibles para él mismo, puede “derivar” en la actividad ilícita (Matza, 2014). La función del referente socio-comunitario es, pues, la de generar otro tipo de condiciones que permitan al joven no llegar a la instancia del delito.

\section{CONCLUSIONES}

Los discursos de referentes comunitarios en torno a la categoría de responsabilidad juvenil no son homogéneos, como tampoco lo son las estrategias que elaboran las instituciones de la comunidad que trabajan en articulación con el CRPJ. Los discursos socio-comunitarios de instituciones con perspectiva de derechos, tales como el CAP, el programa JMMT, el Centro Cultural de la Juventud y el programa Envión, se centran en destacar la necesidad de fomentar el autovalimiento del joven y de implementar mecanismos de acompañamiento y corresponsabilidad. Un discurso que se halla en línea con la matriz cultural del derecho penal clásico, pero aggiornada, podríamos decir, a la matriz de los derechos del niño.

Las dificultades con las que los operadores se enfrentan remiten a la exclusión de (otras) instituciones de la comunidad (principalmente de la escuela), la estigmatización hacia los jóvenes por parte de vecinos del propio barrio y la carencia de integralidad en la vinculación interinstitucional para garantizar el acceso de los jóvenes a derechos (“corresponsabilidad”).

El “autovalimiento" del joven sólo es posible en reciprocidad con la actuación de los miembros de su comunidad, quienes, en la medida en que lo reconocen como uno de los nuestros (y no ya como "el pibe de la esquina"), lo habilitan para concebirse como ciudadano y no como merecedor de una posición subalterna, lo cual, vale aclarar, no lo libera de ella. De hecho, cuando los jóvenes no son acompañados integralmente, por ejemplo, como en el caso del programa JMMT, un programa que fomenta la responsabilidad laboral mediante la inserción en el mundo del trabajo, independientemente del proceso penal que los jóvenes estén atravesando, falla, pues, cuando se interrumpe, los operadores no lo advierten y, a la larga, se descontinúa. 
La disputa se da en cada ámbito, con cada uno de sus actores y, por lo general, fracasa. De ahí que subrayemos el carácter central del acompañamiento de los operadores para contribuir a aminorar el sentimiento de frustración del joven al ser expulsado de las instituciones, sobre todo de la escuela, reforzando a través del diálogo, la escucha y la palabra, su capacidad de imaginarse en una situación deseada.

La referenciación entre el joven y el agente socio-comunitario depende, ante todo, del vínculo que este último establezca con un sujeto en particular cuya principal función será escucharlo, no tanto para comprender los motivos que lo llevaron a violar la ley, sino para orientarlo en cómo tomar decisiones acertadas, cómo ser amable con los demás, en qué personas confiar, cómo cuidarse y respetarse a sí mismo, etc.: acciones educativas, formativas y afectivas que exceden el rol técnico e institucional, y dejan ver el carácter político que dirige el accionar de los agentes, en su heterogeneidad. En este punto, se puede subrayar que de todas las instituciones visitadas, ninguna funciona como sede de una organización política ni los agentes se hallan orgánicamente insertos en una estructura partidaria o un movimiento social. La intervención no es concebida por ellos en términos militantes, sino técnico-profesionales, en su carácter ético, político y moral, y de ningún modo, judicial o penal.

En suma, el análisis del modo en que se desarrollan las medidas no privativas de libertad en la comunidad permite afirmar que las políticas públicas desarrolladas en instituciones con perspectiva de derechos no resultan estigmatizantes para los jóvenes, sobre todo si se mantiene el secreto profesional y, más aún, si el joven acudía a la institución con anterioridad a la apertura de la causa penal. La permanencia en ellas se debe a esos factores, pero remite, principalmente, al vínculo generado con algún referente del espacio. Esto es importante, pues, como sostiene Becker (2014), la extensión de la "carrera criminal" varía de acuerdo con la reacción social que señala como marginales a personas que han cometido "una mala acción etiquetada públicamente como tal" (p. 181).

Pensamos que el rol que los agentes comunitarios juegan en el acompañamiento territorial es central para que la construcción de prácticas socio-educativas alternativas a la privación de la libertad logren atenuar los efectos criminógenos a los que se hallan expuestos, permanentemente, los jóvenes en la comunidad (Rodríguez Alzuelta, 2012). Sólo bajo estas condiciones, las prácticas comunitarias de MAPL pueden operar sin regenerar, bajo nuevas formas, los mecanismos punitivos de control social que tienen lugar bajo medidas privativas de libertad, tal como propone Cohen (1979) en un estudio sobre las redes de supervigilancia en la ciudad. De otro modo, "las sanciones en la comunidad, no habrían logrado reemplazar la cárcel como respuesta, sino que habrían supuesto expandir 
el sistema penal a áreas tradicionalmente ajenas a éste, y por ende, ampliar el control social formal sobre personas tradicionalmente ajenas al mismo” (p. 339).

Si el sistema carcelario resulta un sitio inapropiado para la confrontación del joven con su responsabilidad (Foucault, 2002), entendemos que la generación de políticas públicas en instituciones de la comunidad, con perspectiva de derechos y que no etiquetan al joven como portador de una MAPL, habilitan la construcción de responsabilidad social. Que ello suceda depende en gran medida de los vínculos construidos entre los jóvenes y "referentes" de la comunidad.

\section{REFERENCIAS}

Alabarces, P. y Rodríguez, MA. G. (Comp.) (2008). Resistencias y mediaciones. Estudios sobre cultura popular. Buenos Aires: Paidós (Estudios de comunicación, 28).

Alfieri, E. y Olmos, MA. B. (2010). La estrategia socioeducativa como nuevo modo de intervención en institutos de menores. Avances y persistencias en las agencias de control social penal para adolescentes y jóvenes. Delito y Sociedad. Revista de Ciencias Sociales, 19 (29).

AXAT, J. (2014). Aportes críticos sobre los proyectos penales juveniles para Santa Fe. Recuperado de http: / / cort.as/-8quB.

. (2013). Una voz no menor: Apuntes etnográficos sobre la justicia penal juvenil. Tesis de posgrado, Universidad Nacional de La Plata, Facultad de Humanidades y Ciencias de la Educación. Recuperado de http: / / cort.as/-8quM.

BeCKer, H. (2014). Outsiders. Hacia una sociología de la desviación. Buenos Aires: Siglo XXI Editores.

Bourdieu, P. (1990). La 'juventud' no es más que una palabra. En BourdiEu, P. Sociología y cultura. México: Grijalbo.

CoHen, S. (1979). The punitive city: Notes on the dispersal of social control. Contemporary Crises, 3 (4), pp. 339-363.

Daroqui, A., LÓPEZ, A. y GArcía R., C. (2012). Sujeto de castigos. Hacia una sociología de la penalidad juvenil. Rosario: Homo Sapiens.

y Guemureman, S. (1999). Los «menores» de hoy, de ayer y de siempre: un recorrido histórico desde una perspectiva crítica. Delito y Sociedad. Revista de Ciencias Sociales (13).

DusCHATZKY, S. (1996). La escuela como frontera. Buenos Aires: Paidós.

FOUCAUlt, M. (2002). Vigilar y castigar: nacimiento de la prisión. Buenos Aires: Siglo XXI Editores. 
Fridman, D., Graziano, F. y Jorolinsky, K. (2008). Informe sobre el Régimen Procesal Penal Juvenil de la Ciudad Autónoma de Buenos Aires. Recuperado de: http: / / cort.as/-8qvU.

García MÉndez, E. y Vitale, G. (Comp.) (2009). Infancia y Democracia en la Provincia de Buenos Aires. Comentario crítico sobre las leyes 13.298 y 13.634. Buenos Aires: Fundación Sur Argentina.

GonzÁlez, A. (2015). Discursos y prácticas en el Sistema de Responsabilidad Penal Juvenil: análisis de la implementación de las medidas alternativas a la privación de la libertad en el Centro de Referencia Penal Juvenil de Tandil. Tesis para optar por el título de Licenciada en Trabajo Social. Universidad Nacional del Centro de la Provincia de Buenos Aires-Facultad de Ciencias Humanas.

Guemureman, S., Fridman, D.; Graziano, F.; Jorolinsky, K.; LÓPeZ, A.; Pasin, J. y SAlgado, V. (2010). Dispositivos de privación de libertad y lógica de gobierno intramuros para adolescentes: laberintos de derechos sin sujetos. En Actas de la II Reunión Nacional de Investigadoras / es en Juventudes Argentina.

HALl, S. (1984). Notas sobre la desconstrucción de «lo popular». Recuperado de http://cort.as/$8 \mathrm{qw}$.

Insaurralde, N. y Silva Pelosi, M. (2008). Notas críticas sobre la transición hacia el Sistema de Responsabilidad Penal Juvenil de la Provincia de Buenos Aires. En Actas de las V Jornadas de Sociología de la Universidad Nacional de La Plata. Facultad de Humanidades y Ciencias de la Educación.

KeSSLER, G. (2010). Sociología del delito amateur. Buenos Aires: Paidós. . (2004). De proveedores, amigos, vecinos y barderos. Acerca del trabajo, delito y sociabilidad en jóvenes del Gran Buenos Aires. Desacatos (14), pp. 60-84.

LEACH, E. (1993). Cultura y Comunicación. La Lógica de la Conexión de los Símbolos. Madrid: Siglo XXI.

LÓPEZ, A. (2009). Cuerpo y sujeto del encierro: Abordaje exploratorio sobre un dispositivo institucional de máxima seguridad para adolescentes con causas penales en la Provincia de Buenos Aires. En Seminario Antropología de la subjetividad: estudio desde las alquimias corporales, los rituales y el habitus. Universidad de Buenos Aires-Facultad de Ciencias Sociales.

, Huber, B., Fridman, D., Graziano, F., Pasin, J., Azcárate, J.. Jorolinsky K. y Guemureman, S. (2009). Reflexiones críticas sobre medidas alternativas a la privación de libertad para adolescentes en conflicto con la ley penal. En Actas del. XXVII Congreso de la Asociación Latinoamericana de Sociología. VIII Jornadas de Sociología de la Universidad de Buenos Aires. Asociación Latinoamericana de Sociología. 
LÓPEZ, L. y PADiLla, A. (2013). Responsabilidad adolescente y prácticas «psi». Relaciones «peligrosas». En Gonzáles Laurino, C., Leopold Costábile, S., López Gallego, L. y Martinis, P. (Coord.), Los sentidos del castigo. El debate uruguayo sobre la responsabilidad en la infracción adolescente. Montevideo: Universidad de la República.

Lucesole, N. (2012). Políticas Públicas de Niñez y Adolescencia en la provincia de Buenos Aires. Análisis del proceso de implementación del Sistema de Responsabilidad Penal Juvenil: un estudio de caso en el Centro de Referencia La Plata. Tesis de Magíster en Diseño y Gestión de Políticas y Programas Sociales. FLACSO.

MATZA, D. (2014). Delincuencia y deriva. Cómo y porqué algunos jóvenes llegan a quebrantar la ley. Buenos Aires: Siglo XXI Editores.

MigueZ, D. (2003). Rostros del desorden. Fragmentación social y la nueva cultura delictiva en sectores juveniles. En GAYOL, S. y Kessler, G. (Comp.), Violencias, delitos y justicias en la Argentina. Buenos Aires: Manantial/UngS.

Miller, W. (1958). Lower Class Culture as Generating Mileu of Gang Delinquency. En Journal of Social Issues, 14 (3).

Pegoraro, J. (2002). Notas sobre los jóvenes portadores de la violencia juvenil en el marco de las sociedades pos-industriales. Revista Sociologías (8).

RECEPTER, C. (2012). Juventud y feminidad: notas para abordar el estudio de las subjetividades femeninas en contextos de exclusión social. En Actas de la III Reunión Nacional de investigadores / as en Juventudes Argentina / Viedma.

Rodríguez AlzueTA, E. (2012). Circuitos carcelarios: el encarcelamiento masivo-selectivo, preventivo y rotativo en la Argentina. Question, 1 (36).

TONKOnOfF, S. (2007a). Juventud, exclusión y delito. Notas para la reconstrucción de un problema. Revista Alegatos (65), pp. 33-46.

- (2007b.). Tres movimientos para explicar por qué los pibes chorros visten ropas deportivas. La sociología ahora. Buenos Aires: Siglo XX.

URiarte, C. (2013). La cuestión de la responsabilidad en el derecho penal juvenil. En Laurino, C., Leopold, S., López G., L. y Martinis. P. (Coord.), Los sentidos del castigo. El debate uruguayo sobre la responsabilidad en la infracción adolescente. Montevideo: Universidad de la República. 